IP Periodica Polytechnica

Mechanical Engineering

62(4), pp. 298-304, 2018

https://doi.org/10.3311/PPme.12263

Creative Commons Attribution (i)

RESEARCH ARTICLE

\section{Scour around Bridge Piers: Numerical Investigations of the Longitudinal Biconcave Pier Shape}

\author{
Bouabdellah Guemou ${ }^{1 *}$, Abdelali Seddini², \\ Abderrahmane Nekkache Ghenim ${ }^{2}$
}

Received 21 March 2018; accepted after revision 06 July 2018

\begin{abstract}
The flow pattern around a bridge pier and the scouring phenomenon are very complicated. The basic mechanism causing local scour is the down-flow at the upstream face of the pier. It is understood that the horseshoe vortex is the key mechanism that leads to the local scour around pier; existing literature revealed that the strength of the down-flow, horseshoe vortex and the wake vortex are greater in the case of square piers compared to circular piers.

In this paper we have investigated a new longitudinal biconcave bridge pier shape that reduces better the bed shear stress. For that purpose, a number of numerical simulations have been carried out using a Finite Volume Method (FVM) and for the turbulence model we have chosen the Detached Eddy Simulation (DES) for its capability to capture the rich dynamics of the horseshoe vortex at the upstream junction between the pier and the bed.

The present study shows that the new longitudinal biconcave bridge pier shape reduces $10 \%$ to $12 \%$ the bed shear stress at the junction between the pier and the bed in other hand this shape increases the bed shear stress about $20 \%$ but at a distance of $D$ downstream the bridge pier in the flow direction.
\end{abstract}

\section{Keywords}

scour, bridge pier, longitudinal shape, simulations

\section{Introduction}

When a pile is placed in an erodible bed, scour phenomena will take place around it, due to the action of waves and currents. The pile scour is a complex process, in which the main element is the horseshoe vortex [1]. It causes an increase in local sediment transport capacity and this consequently leads to scour in the vicinity of the structure, this is referred to as local scour in literature (Fig. 1).

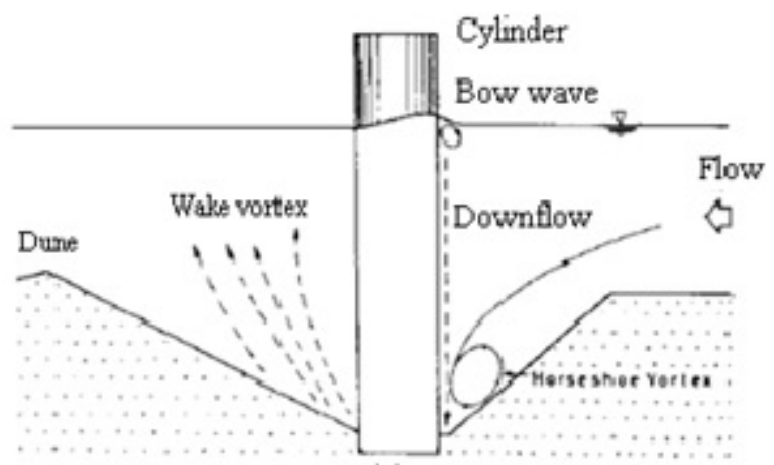

(a)

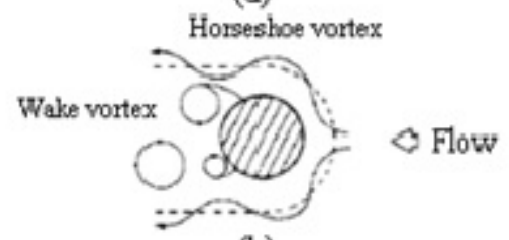

(b)

Fig. 1 The flow and scour pattern around a circular pier

Even if scouring process is a natural phenomenon, local scouring around bridge piers is a significant problem that threatens the hydraulic bridges [2]. Local scour has been identified as one of the key factors that cause failures of structures in bridge engineering, coastal and offshore engineering. As reported in the literature, a series of relatively recent bridge failures because of pier scour [3], and over the last 30 years in the United States, one thousand bridges have collapsed because of hydraulic failure [4].

Scouring phenomena is a significant problem for bridge engineering. There are several ocean and coastal structures located in rivers, sea and streams that may be prone to erosion 
due to combinations of scouring factors. It is believed that erosion in cohesive bed materials occurs when the fluid shear stress is sufficient to overcome the tensile strength of the bed material and submerged unit weight of the soil [5].

Local scour has been identified as one of the key factors that cause failures of structures in bridge engineering, coastal and offshore engineering. As reported in the literature, a number of relatively recent bridges failures because of pier scour [3], and over the last 30 years in the United States, one thousand bridges have collapsed because of hydraulic failure [4]. Even if the scouring process is a natural phenomenon, the local scouring around bridge piers is a significant problem that threatens the hydraulic bridges [2].

Local scour is caused by the formation of the horseshoe vortex (HSV) at their base (Fig. 1). The HSV is caused by the accumulation of water in the junction between the pier and the bed on the upstream face of the bridge pier resulting in increased shear stress and hence an increase in sediment transports capacity of the flow [6]. So, it is the down-flow impinging on the bed which is the main scouring agent. [1]

Numerous studies on local scour around vertical piles in steady currents have been reported in the past. Most of these studies deal with laboratory model investigations.

From experimental studies, it is seen that formulating mathematical approaches cannot present the scour depth with suitable accuracy. Occasionally, the scour depth at pile foundations is predicted using empirical equations yielded for simple piers. [8]

Empirical equations obtained by experimental observations are not accurate enough to predict the scour depth. This is mainly due to the complexity of the phenomena. Recently, different artificial intelligence approaches such as Artificial Neural Networks (ANNs), Genetic Programming (GP), GeneExpression Programming (GEP), Model Tree (MT), and Group Method of Data Handling (GMDH) have been used to solve scour problem around hydraulic structures. [9]

The studies of turbulence around obstacle have started with laboratory experiments [10]. While much has been written on the subject of flow and scour in steady currents, only few studies have presented the three dimensional numerical modeling of these processes [11]. In fact, these studies have treated the flow pattern on a flat rigid bed. [12]

The main objective of this study is to discuss the capability of a new longitudinal bridge pier shape to reduce the down flow intensity and so the bed's shear stress.

Numerical studies about scour around a vertical circular cylinder are not well documented as experimental investigations, mostly due to the limitation of available computer capacities to the scour research community. The advantage of the numerical method is that it is free from the scaling effect as it can be run in the prototype size. However, numerical models do need to use empirical formulae for sediments. [13]
In this paper we have simulated the flow around bridge piers using the DES turbulence model. Two shapes have been simulated: circular uniform and longitudinal aerodynamic shape.

We have simulated the flow past a vertical circular cylinder mounted at the bottom of a rectangular channel. A similar configuration was studied experimentally by Dargahi [14] who carried out flow visualizations experiments for the range of Reynolds numbers between 6600 and $65 \times 103$ based on the cylinder diameter and the flow approach.

\section{Numerical simulations}

The mechanisms of scour around bridge piers are still under investigations. Numerical models are often used for turbulent flow investigations [15]. Flow observations reveal that a complex flow pattern occurs even in the case of a simple geometric hydraulic structure [16]. The main purpose of a numerical simulation around bluff bodies such as bridge piers is to estimate the bed's shear stress and consequently the scour hole. [17]

Existent bridges need to be protected against scour, in this section we have discussed a new geometric alternative that may reduce the bed shear stress, and we proposed an alternative for the longitudinal shape of the bridge pier.

We have found that the down flow is responsible of the Horse Shoe Vortex, that one is also responsible of scour around bridge piers.

In this section we have reduced the down flow that creates the vortex horseshoe by expanding the bottom and the top of the bridge pier. The Fig. 4 below presents the shape of the original bridge pier and the new longitudinal alternative of the pier. During the numerical work conducted in this section we have varied the enlargement up and down with keeping the original pier width in the middle. We thought about adding cone up and down the bridge pier to force the down flow to pass through the middle section where the bridge pier gets thin and this reduces the bed shear stress.

In this section we present the turbulence model, the geometric setup and the boundary conditions used along all simulations.

\subsection{The governing equations}

Throughout the past several decades, numerical models have been paid more and more attention for turbulent flow studies. The three-dimensional Navier-Stokes and continuity equations can be written as follows:

$$
\begin{gathered}
\frac{\partial \bar{u}_{i}}{\partial x_{i}}=0 \\
\frac{\partial \bar{u}_{i}}{\partial t}+\frac{\partial \bar{u}_{i} \bar{u}_{j}}{\partial x_{j}}=-\frac{1}{\rho} \frac{\partial \bar{P}}{\partial x_{i}}+\vartheta\left(\frac{\partial^{2} \bar{u}_{i}}{\partial x^{2}}\right)+\left(\frac{\partial \tau_{i j}}{\partial x_{j}}\right) .
\end{gathered}
$$

Where $x_{i}=1,2,3$ denotes the stream-wise, span-wise and vertical directions, respectively, $\bar{u}_{i}$ time averaged or filtered velocity 
components in the mentioned directions, $\bar{P}$ time averaged or filtered pressure, $\rho$ the density, $\vartheta$ the kinematic viscosity of the fluid, and $\tau_{i j}$ Reynolds shear stresses or sub-grid shear stresses.

\subsection{Turbulence model}

Numerical simulations of junction flows are particularly challenging especially if the objective is to capture the dynamic features of the horseshoe vortex (HSV) observed in the experiments of high Reynolds numbers. Steady and Unsteady Reynolds Average Navier Stokes simulations (RANS and URANS) have naturally failed to capture the unsteadiness of the HSV system. [18]

Even though URANS calculations have demonstrated reasonable agreement in the prediction of time average quantities, hybrid methods that combine URANS predicting the unsteady features of massively separated flows at realistic Reynolds numbers provide best results.

Detached Eddy Simulations (DES), a hybrid model proposed by Spalart et al. [19] and based on the Spalart-Allmaras turbulence model, has been able to capture the unsteadiness of the HSV system as reported in the recent study by Paik et al. [20]

Paik et al. [20] successfully resolved the main flow, turbulence statistics and bimodal velocity dynamics for the flow past the wall-mounted wing studied experimentally by Devenport and Simpson at $\mathrm{Re}=1.15 \times 105$. [18]

The turbulence model used in this research to simulate the flow around bridge piers is the Detached Eddy Simulation (DES).

\subsection{Geometric setup}

The geometric setup for the numerical simulation is shown in Fig. 2. The grids of the computational domain are more concentrated around the bridge pier and near the symmetric axis at the bed due to complexity of the flow pattern in this region (Fig. 3).

The domain is $1 \mathrm{~m}$ length, $0.2 \mathrm{~m}$ width and $0.1 \mathrm{~m}$ high. The pier diameter is $\mathrm{Dp}=0.04 \mathrm{~m}$, we have fixed this diameter value to get a Reynolds number based on the pier diameter equal to 39000 and so to make comparison to the work of Dargahi [14]. The inlet was placed at $12 \mathrm{D}$ from the pier and the type of the boundary was set as velocity inlet (a velocity profile is applied to accelerate convergence).

Most of cells in the 3D grid are hexahedral elements. An aspect ratio of about 4 to 5 is observed. For all geometric configurations the number of cell is about 580000 cell.

We have first simulated the flow around the circular cylinder, and then we have re-meshed the new domain with the new longitudinal shape (Fig. 4) using the same boundary conditions and the same turbulence model.

The new longitudinal shape consists of two cones up and down the bridge pier with a diameter of $1.5 \mathrm{D}$ with $\mathrm{D}$ the pier's diameter, the cone diameter decreases until the middle of the pier then it increases. The Fig. 4 presents the original circular bridge pier and the new geometry.

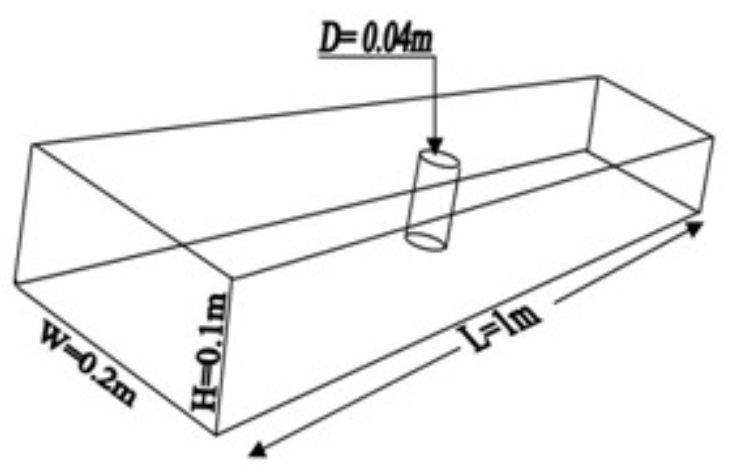

Fig. 2 Geometric setup for the circular bridge pier simulations

\section{A)}

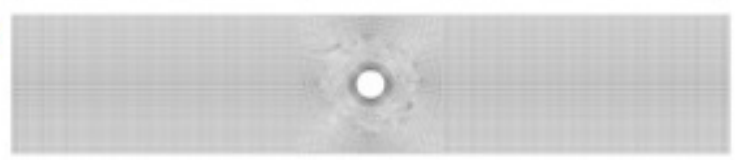

B)

Fig. 3 Computational grid for 3D numerical simulation of flow around circular bridge pier. a) Top view, b) Mesh near the bridge pier

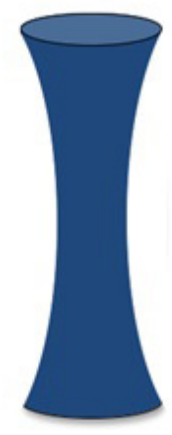

(a)

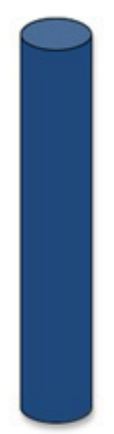

(b)
Fig. 4 The bridge pier shapes, a) the longitudinal concave bridge pier shape with up and down with $1,5 \mathrm{D}, \mathrm{b}$ ) circular pier with $\mathrm{D}=0.04 \mathrm{~m}$

\subsection{Boundary conditions}

The inflow consists of a velocity inlet and its located upstream of the bridge pier, at a distance of $12 \mathrm{D}(\mathrm{D}$ is the pier diameter). The outlet's boundary condition consists of a pressure outlet with zero for the gauge pressure value and it's located at $12 \mathrm{D}$ downstream of the bridge piers. The left, right and bottom boundaries are set as a smooth wall with no slip condition and the top is set as a symmetry condition (Fig. 5). 


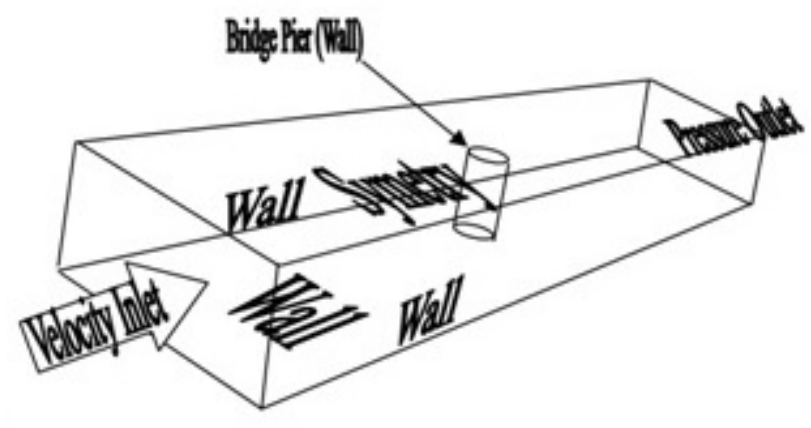

Fig. 5 Boundary conditions

The roughness high of the left and right walls and also this of the bridge pier are set to zero.

The Reynolds number based on the pier diameter is $\mathrm{ReD}=39 \times 10^{3}$ and the Reynolds number based on the velocity inlet is $\mathrm{Re}=195$ 920. We have given to the bed roughness a value of $0.001 \mathrm{~m}$ to simulate the soil interface.

For the velocity profile, we have launched simulations with a uniform velocity inlet of $0.9796 \mathrm{~m} / \mathrm{s}$, then after 100 second we have extract the velocity profile at $8 \mathrm{D}$ from the inlet and we have launched again simulations under this new condition (velocity profile in the inlet), we have used the same velocity profile in all simulations, we have observed that this velocity profile have make convergence easier and we have get lower converging time.

As explained previously, DES needs a finer mesh to provide an exact solution and with about 580000 elements in every geometry mesh, this conditions makes the calculation times enormous (calculations were launched on CPU Core 2 Duo with 1 GB RAM).

Flowing water can excavate and carry away materials from the river bed and from around the bridge piers, thus resulting in scour hole. In this paper we focus on the bed shear stress because the launching of the scour is linked to this factor, for this purpose we have run numerical simulations then we have compared the velocity profiles and the bed shear stress for all configurations (the circular uniform and longitudinal aerodynamic bridge piers).

\section{Results and discussions}

An important engineering application of turbulent junction flows is in the area of bridge foundation scour in natural rivers where increased values of the bed shear induced by the downflow decrease the security of the structure.

Several authors have studied the flow field around different pier geometries like geometries with square and rectangular cross-sections mounted on a flat rigid bed. Dey et al. [21], Graf and Istiarto [16] and Roulund et al. [11] investigated the mean flow and the turbulence kinetic energy distribution inside the equilibrium scour hole around cylindrical piers. [12]

A recent comprehensive study was reported by Unger and Hager [22] who carried out particle image velocimetry (PIV) experiments of bridge pier flows over a wide range of Reynolds numbers. They found that a strong downward flow in the front of the cylinder and the HSV is the main culprit for the initiation and subsequently growth of the scour hole. They also reported that the primary contribution to the local scour occurs in the region located in front of the pier where the flow is dominated by the energetic turbulent HSV system. [22]

We have run numerical simulations under the same hydraulic conditions (the Reynolds number and flow configuration) and numerical conditions (the same turbulence model, boundary conditions and similar mesh) all this to be able to make comparison. We have meet a problem when making the new bridge pier mesh that satisfies the conditions of good mesh due to its irregularity in term of geometry. The turbulence model is the DES with the same boundary conditions; we have lunched the calculations for 39,000 seconds. In this section we present the results of the numerical simulations for the two geometric configurations.

At what follows, we present and discuss the results for each case and we compare the configurations.

\subsection{Model validation}

The model with circular pier has been validated against the experiments of others. We principally compared the pressure along the symmetry line in the $\mathrm{x}$ axis. The $C p b$ in Fig. 6 is defined as $C p b=P / P b$ with $P$ being the pressure and $P b$ being the pressure at the toe of the stagnation line (the cylinder's most upstream edge).

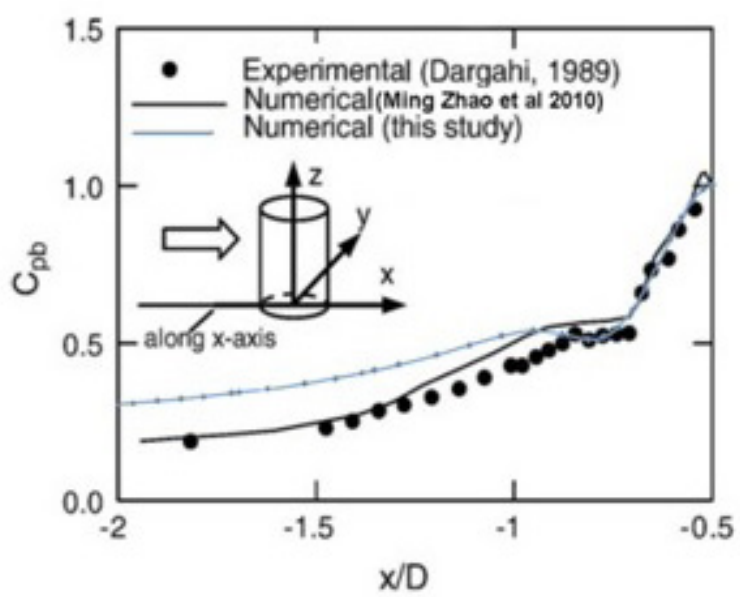

Fig. 6 Pressure distribution upstream the bridge pier

The difference in pressure between the top and the bottom of the cylinder drives the flow downward and forms the horseshoe vortex.

Fig. 6 shows the comparison between the results of the present simulation (circular pier) results with the pressure measurements of Dargahi [14] and the numerical work of Zhao et al. [13]. It also shows that the numerical and the experimental results agree well. A relative constant pressure distribution between $-1<\mathrm{x} / \mathrm{D}<-0.75$, referred as a plateau by Dargahi [14] is attributed to the presence of the horseshoe vortex. This plateau was well predicted by the present numerical 
model. The little difference between the model simulation and the measurements $(-2<\mathrm{x} / \mathrm{D}<-1)$ is due to the grid density and overall the curve explains well the horseshoe mechanism.

\subsection{The position of the maximum bed shear stress}

Fig. 7 presents the Variations of the bed shear stress around a circular bridge pier, the maximum bed shear stress is located at the neighboring area of the bridge pier at about $75^{\circ}$ and $82^{\circ}$ (symmetrically) from the plane of symmetry in the flow direction

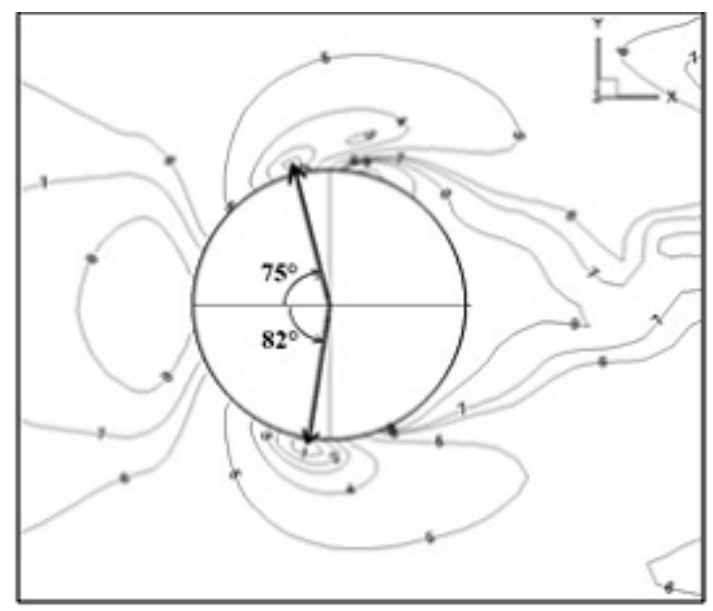

Fig. 7 The location of the maximum bed shear stress around circular bridge pier

These observations have been confirmed by the work of Oliveto and Hager [23], as "scour always starts at an angle of about $75^{\circ}$ from the channel axis". [22]

This comes in concordance with the maximum velocity observed at the same angles around the bridge pier.

In the Fig. 7, the contour numbers are classified from the higher bed shear stress (correspond to the value $1=31.98 \mathrm{~Pa}$ ) to the lower bed shear stress (correspond to the value $9=0.035 \mathrm{~Pa}$ ).

\subsection{Influence of the longitudinal bridge pier shape on the bed shear stress}

The reduction of the scour around obstacles has taken too much research. Numerical and experimental researches on the subject have been carried out and few countermeasures have been proposed.

It is understood that the horseshoe vortex is one of the key mechanisms that leads to the local scour around bridge pier. Existing literature reveals that the strength of the down-flow, the horseshoe vortex and the wake vortex are greater in the case of square piers compared to circular piers. In addition to the square shape, the circular and the round-nosed shapes are the common shapes that are used in the bridge pier design. As noted in the literature, it is the square shape that had higher risk of scour between the three shapes. [3]

The purpose of this numerical simulation was, first of all, to obtain a detailed description of the flow pattern around the bridge pier, then to investigate the influence of the longitudinal bridge pier's shape on the bed shear stress around the river structure.

In the two cases we have displayed the wall's shear stress on the bed and we have first observed that in the original circular pier the maximum shear stress is always near the vertical cylinder, on the other hand we have observed that the longitudinal aerodynamic shape has reduced the bed shear stress $10 \%$ to $12 \%$ near the pier but this shape increases the bed shear stress about $20 \%$ but at a distance of $\mathrm{D}$ downstream the bridge pier in the flow direction.

Numerical simulations indicate that the bed shear stress depends strongly on the bridge pier shape as confirmed from experimental researches. In another hand, it is through the Figs. 8 and 9, that we can see the influence of this new geometry on the flow around bridge pier. The objective of this configuration is to break the down flow. Fig. 8 shows that the maximum of the shear stress around the original bridge pier is $0.578 \mathrm{~Pa}$ against $0.708 \mathrm{~Pa}$ where the geometry is modified but this value is observed at a distance equal to $\mathrm{D}$ upstream the bridge pier which is a positive result knowing that around the bridge pier a reduction of $10 \%$ to $12 \%$ is observed.

The pressure distribution on the stagnation line is plotted in Fig. 10, we have examined the down flow behavior on the upstream face of the two geometries of the bridge pier.

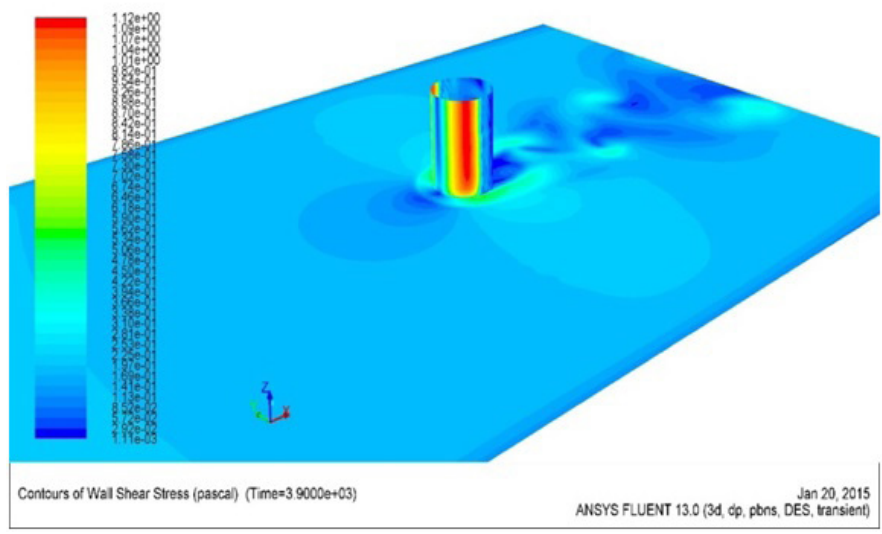

Fig. 8 The bed shear stress around circular bridge pier

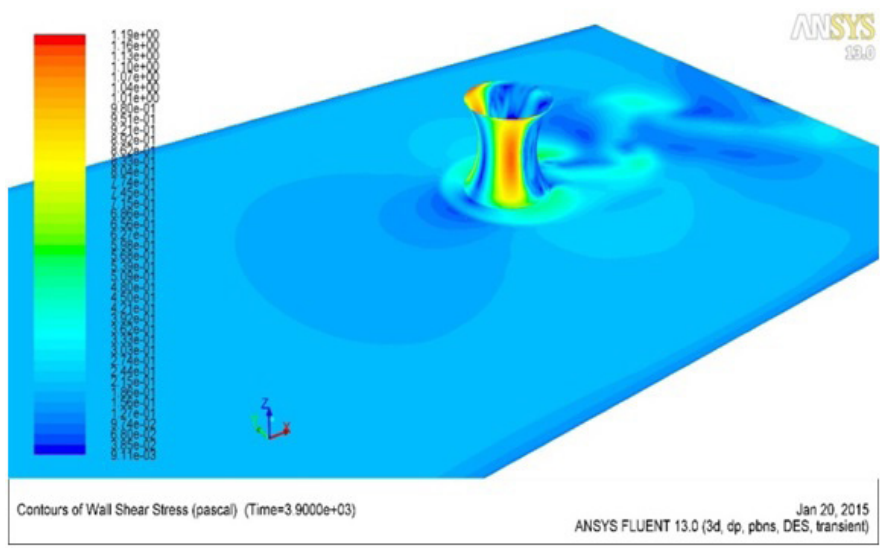

Fig. 9 The bed shear stress around the longitudinal biconcave bridge pier shape 


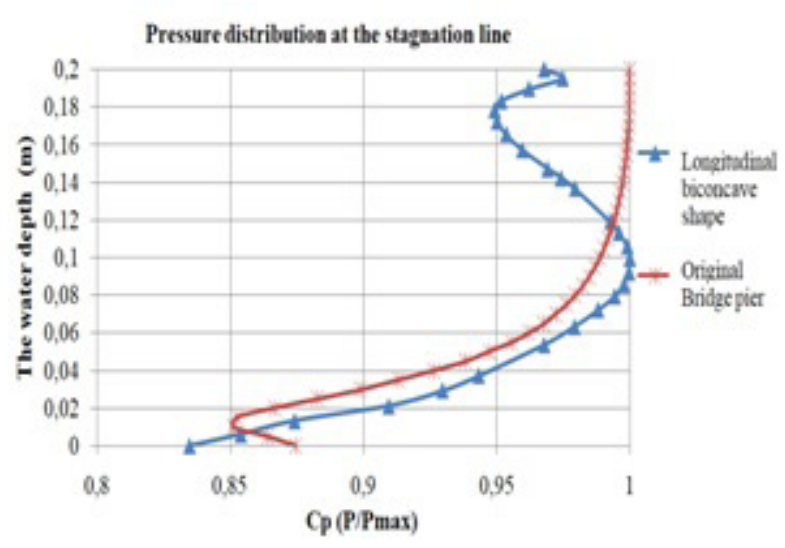

Fig. 10 Pressure distribution at the stagnation line (original pier and the new longitudinal shape)

When the flow reaches the bridge pier, it dives towards the junction of the bridge pier with the river bed thus creating a downward flow which increases in speed as it approaches the bed; the vortex is a consequence of contact with the bed.

The Fig. 10 presents the curve of the pressure distribution at the stagnation line better explains the mechanisms of the down flow. At $h=0.2 \mathrm{~m}$ we have the maximum of pressure when $h$ decreases the pressure decreases. The pressure gradient creates a water flow down, as the gradient increases the vertical velocity also increases, until $0<h<0.02 \mathrm{~m}$ where the pressure decreases, it is in this area where the vortex occurs.

In the new geometry, the pressure distribution has changed and we have divided the vertical flow into two part, the first part $0<h<0.1 \mathrm{~m}$ where the flow is down and the second one is where $0.1 \mathrm{~m}<h<0.2 \mathrm{~m}$ where the flow is up.

For the first part the down flow is for short distance without its full intensity because the upper part of the flow is up flow, so we have got less velocity and less bed shear stress, the results of this change in direction at the stagnation line is a reduction in the shear stress at the bottom, the new geometry was able to reduce the bed shear stress of 10 to $12 \%$ around the bridge piers but it increases of $20 \%$ downstream of the bridge pier, at a distance equal to $\mathrm{D}$ as shown in Fig. 11.

First of all, the crucial parameter in the developing of the scour hole is the down-flow and therefore the horseshoe vortex, so the reduction of the scour must pass by the reduction of the down-flow intensity.

The most important observation is that the flow decelerates as it approaches the cylinder coming to rest at the face of the pier. The associated stagnation pressures are highest near the surface, where the deceleration is the greatest, and decrease downwards. In response to the downwards pressure gradient at the pier face, the flow reaches a maximum just below the bed level.

Furthermore, numerical simulations indicate that in the case of the new geometry, it has been observed that toward the pier, the flow is strongly deflected in the vertical direction,

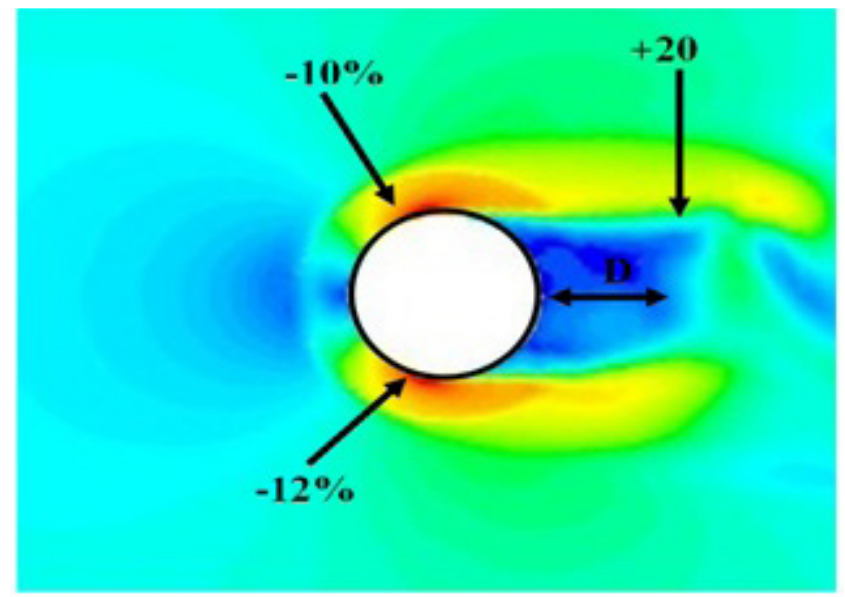

Fig. 11 Influence of the new geometry on the bed shear stress

resulting in two vertical jets directly at the pier front starting from the stagnation point. The upper jet, the so-called up-flow, is directed to the water surface whereas the lower jet, the downflow, towards the sediment surface.

The up-flow induces a surface recirculation and the downflow is deflected against the main flow direction resulting finally in the so-called initial vortex close the bed [22].

In this paper we have found that the longitudinal shape reduces better the bed shear stress even if it gets higher but at a distance of $\mathrm{D}$ upstream the bridge pier.

The relation between the bridge pier shape and the bed shear stress proposed in this paper is promising and experimentations in that field provide more details that can help to control the scour around bridge piers.

\section{Conclusion}

The purpose of this numerical simulation was, first of all, to obtain a detailed description of the flow pattern around the bridge pier, then to investigate the influence of the longitudinal concave bridge pier's shape on the bed shear stress around the river structure.

First, the basic knowledge on the flow is confirmed. DES has been shown to be an efficient way for modeling turbulent flow around obstacle, but it requires high computer resources.

Then, in the two cases we have displayed the wall's shear stress on the bed and we have first observed that in the original circular pier the maximum shear stress is always near the vertical cylinder, on the other hand we have observed that the longitudinal concave shape has reduced the bed shear stress $10 \%$ to $12 \%$ near the pier but this shape increases the bed shear stress about $20 \%$ but at a distance of $\mathrm{D}$ downstream the bridge pier in the flow direction.

Furthermore, numerical simulations indicate that in the case of the new geometry, it has been observed that toward the pier, the flow is strongly deflected in the vertical direction, resulting in two vertical jets directly at the pier front starting from the stagnation point. The upper jet, the so-called up-flow, is 
directed to the water surface whereas the lower jet, the downflow, towards the sediment surface.

Discussion of the new longitudinal bridge pier shape proposed in this paper needs more experiments that can provide more details to help control the scour around bridge piers.

\section{References}

[1] Najafzadeh, M., Barani, G.-A., Hessami-Kermani, M.-R. "Group method of data handling to predict scour depth around vertical piles under regular waves." Scientia Iranica. 20(3), pp. 406-413. 2013. https://doi.org/10.1016/j.scient.2013.04.005

[2] Najafzadeh, M., Barani, G.-A. "Comparison of group method of data handling based genetic programming and back propagation systems to predict scour depth around bridge piers." Scientia Iranica. 18(6), pp. 1207-1213. 2011. https://doi.org/10.1016/j.scient.2011.11.017

[3] Wardhana, K, Hadipriono, F. C. "Analysis of Recent Bridge Failures in the United States." Journal of Performance of Constructed Facilities. 17(3), pp. 144-150. 2003. https://doi.org/10.1061/(ASCE)0887-3828(2003)17:3(144)

[4] Masjedi, A., Bejestan, M. S., Esfandi, A. "Reduction of local scour at a bridge pier fitted with a collar in a 180 degree flume bend (Case study: oblong pier)." Journal of Hydrodynamics, Ser. B. 22(5), pp. 669-673. 2010. https://doi.org/10.1016/S1001-6058(10)60012-1

[5] Najafzadeh, M., Barani, G.-A., Azamathulla, H. M. "GMDH to predict scour depth around a pier in cohesive soils." Applied Ocean Research. 40, pp. 35-41. 2013.

https://doi.org/10.1016/j.apor.2012.12.004

[6] Pal, M., Singh, N. K., Tiwari, N. K "M5 model tree for pier scour prediction using field dataset." KSCE Journal of Civil Engineering. 16(6), pp. 1079-1084. 2012. https://doi.org/10.1007/s12205-012-1472-1

[7] Ali, K. H. M., Karim, O. "Simulations of flow around piers." Journal of Hydraulic Research. 40(2), pp. 161-174. 2002. https://doi.org/10.1080/00221680209499859

[8] Najafzadeh, M. "Neuro-fuzzy GMDH systems based evolutionary algorithms to predict scour pile groups in clear water conditions." Ocean Engineering. 99, pp. 85-94. 2015. https://doi.org/10.1016/j.oceaneng.2015.01.014

[9] Najafzadeh, M., Etemad-Shahidi, A., Lim, S. Y. "Scour prediction in long contractions using ANFIS and SVM." Ocean Engineering. 111, pp. 128-135. 2016. https://doi.org/10.1016/j.oceaneng.2015.10.053

[10] Huang, W., Yang, Q., Xiao, H. "CFD modeling of scale effects on turbulence flow and scour around bridge piers." Computers \& Fluids. 38(5), pp. 1050-1058. 2009. https://doi.org/10.1016/j.compfluid.2008.01.029

[11] Roulund, A., Sumer, B. M., Fredsøe, J., Michelsen, J. "Numerical and experimental investigation of flow and scour around a circular pile." Journal of Fluid Mechanics. 534, pp. 351-401 2005. https://doi.org/10.1017/S0022112005004507
[12] Khosronejad, A., Kang, S., Sotiropoulos, F. "Experimental and computational investigation of local scour around bridge piers." Advances in Water Resources. 37, pp. 73-85. 2012.

https://doi.org/10.1016/j.advwatres.2011.09.013

[13] Zhao, M., Cheng, L., Zang, Z. "Experimental and numerical investigation of local scour around a submerged vertical circular cylinder in steady currents." Coastal Engineering. 57(8), pp. 709-721. 2010. https://doi.org/10.1016/j.coastaleng.2010.03.002

[14] Dargahi, B. "The turbulent flow field around a circular cylinder." Experiments in Fluids. 8(1-2), pp. 1-12. 1989. https://doi.org/10.1007/BF00203058

[15] Pasiok, R., Stilger-Szydło, E. "Sediment particles and turbulent flow simulation around bridge piers." Archives of Civil and Mechanical Engineering. 10(2), pp. 67-79. 2010.

https://doi.org/10.1016/S1644-9665(12)60051-X

[16] Graf, W. H., Istiarto, I. "Flow pattern in the scour hole around a cylinder." Journal of Hydraulic Research. 40(1), pp. 13-20. 2002. https://doi.org/10.1080/00221680209499869

[17] Guemou, B., Seddini, A., Ghenim, A. N. "Numerical investigations of the round-nosed bridge pier length effects on the bed shear stress." Progress in Computational Fluid Dynamics, An International Journal. 16(5), pp. 313-321. 2016. https://doi.org/10.1504/PCFD.2016.078753

[18] Escauriaza, C., Sotiropoulos, F. "Reynolds Number Effects on the Coherent Dynamics of the Turbulent Horseshoe Vortex System." Flow, Turbulence and Combustion. 86(2), pp. 231-262. 2011.

https://doi.org/10.1007/s10494-010-9315-y

[19] Spalart, P. R., Jou, W-H., Strelets, M., Allmaras, S. R. "Comments on the Feasibility of LES for Wings, and on a Hybrid RANS / LES Approach." In: Liu, C., Liu, Z., Sakell, L. (eds.) Advances in DNS / LES: Proceedings of the First AFOSR International Conference on DNS / LES. Louisiana, USA, Aug. 4-8, 1997.

[20] Paik, J., Escauriaza, C., Sotiropoulos, F. "On the bimodal dynamics of the turbulent horseshoe vortex system in a wing-body junction." Physics of Fluids. 19(4), pp. 045107/1-20. 2017.

https://doi.org/10.1063/1.2716813

[21] Dey, S., Bose, S. K., Sastry, G. L. N. "Clear Water Scour at Circular Piers: a Model." Journal of Hydraulic Engineering. 121(12), pp. 869876. 1995.

https://doi.org/10.1061/(ASCE)0733-9429(1995)121:12(869)

[22] Unger, J., Hager,W. H. "Down-flow and horseshoe vortex characteristics of sediment embedded bridge piers." Experiments in Fluids. 42(1), pp. 1-19. 2007.

https://doi.org/10.1007/s00348-006-0209-7

[23] Oliveto, G., Hager, W. H. "Temporal Evolution of Clear-Water Pier and Abutment Scour." Journal of Hydraulic Engineering. 128(9), pp. 811820. 2002.

https://doi.org/10.1061/(ASCE)0733-9429(2002)128:9(811)

[24] Debnath, K., Chaudhuri, S. "Local scour around non-circular piers in clay-sand mixed cohesive sediment beds." Engineering Geology. 151, pp. 1-14. 2012.

https://doi.org/10.1016/j.enggeo.2012.09.013 